\title{
Effect of Concentration on Isomerization of Rhodanine Derivatives of Merocyanine Dyes in Polar Solvents
}

\author{
O. P. Dimitriev, ${ }^{1}$ K. P. Grytsenko, ${ }^{1}$ O. I. Tolmachev, ${ }^{2}$ Yu. L. Slominskii, ${ }^{2}$ \\ M. A. Kudinova, ${ }^{2}$ and S. Schrader ${ }^{3}$ \\ ${ }^{1}$ V. E. Lashkaryov Institute of Semiconductor Physics, Prospekt Nauki 41, Kyiv, Ukraine \\ ${ }^{2}$ Institute of Organic Chemistry, 5 Murmanska Street, Kyiv, Ukraine \\ ${ }^{3}$ Institute of Photonics, Laser \& Plasma Technology, University of Applied Sciences Wildau, Bahnhofstraße, Germany
}

Correspondence should be addressed to O. P. Dimitriev; dimitr@isp.kiev.ua

Received 26 May 2014; Revised 5 August 2014; Accepted 7 August 2014; Published 27 August 2014

Academic Editor: Claudio Fontanesi

Copyright (C) 2014 O. P. Dimitriev et al. This is an open access article distributed under the Creative Commons Attribution License, which permits unrestricted use, distribution, and reproduction in any medium, provided the original work is properly cited.

\begin{abstract}
Rhodanine derivatives of merocyanine dyes with residues of 1,3,3-trimethyl-3H-indole and 3-ethylbenzothiazoline have been found to possess two molecular forms in diluted solutions of polar solvents such as dimethylformamide, dimethyl sulfoxide, and Nmethylpyrrolidinone. The first molecular form was observed to prevail at low concentrations of the dyes, normally up to $10^{-5} \mathrm{M}$. The second one prevails at higher concentrations and is displayed through a new band in the electronic absorption spectrum, which is red-shifted with respect to the absorption band of the first form. No similar effect was found for these dyes by use of nonpolar solvents or upon alkyl-substitution of the molecules at nitrogen atom in the rhodanine moiety. We assign the above two forms to different molecular isomers and the analogous spectral changes were shown to take place by light or heat influence which correspond to a typical isomerization effect for the related merocyanine dyes. It is discussed that the isomer transformation is facilitated by the increased mobility of the proton bonded to the nitrogen atom of the rhodanine moiety in the polar environment and the increased amount of dye-dye collisions.
\end{abstract}

\section{Introduction}

Donor-acceptor dyes of the merocyanine type have attracted considerable attention because of their unusual behavior in solutions, where they show a significant solvatochromic shift or multiple absorption bands in the visible region of the spectrum [1]. Explanation of such a complex behavior was a subject of recent debates in the literature. For example, Morley et al. [2] suggested that there are a number of stable nonplanar conformations as well as dimer states in Brooker's merocyanines, which were predicted to absorb at longer and shorter wavelength, respectively, as compared with the planar conformer. Takayanagi et al. [3] revealed the rotational isomerism of the end groups in rhodanine derivatives of merocyanines, which leads to four possible conformers, two of which are stable in cyclohexane. Polar solvents complicate both absorption and emission spectra due to solvatochromism which was assigned to redistribution of the $\pi$-electron density along the molecule due to polarized solvent environment [4]. The solute-solvent interactions were described by the simple solvation model [5], CS INDO scheme [6], all valence electron SCF approach [7, 8], and so forth. Solvatochromic behavior in polar solvents can be negative or positive, that is, inducing the blue or red shift of the absorption and fluorescence band, respectively, as compared to the band in nonpolar solvents, depending on the dye molecular structure [9]. The limiting case of the $\pi$-electron redistribution leads to zwitterionic form of the molecule; however, both zwitterions and neutral forms as a resonance hybrid state can exist in a solution with the different weight ratios of the above forms. Large shifts observed in merocyanines spectra were also assigned to both the dielectric effect of the solvent and its ability to form a hydrogen bond with merocyanine molecule, leading to greater stabilization of a more polar ground state over the first excited state in solvents of high polarity $[10,11]$.

Rotational isomerism which leads to spectral changes of merocyanine monomers is one of the intriguing issues since it 


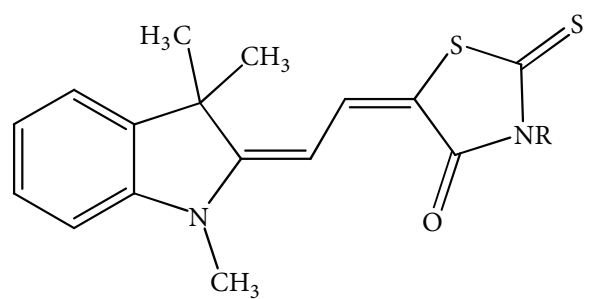

1: $\mathrm{R}=\mathrm{H}$

1a: $\mathrm{R}=\mathrm{C}_{2} \mathrm{H}_{5}$

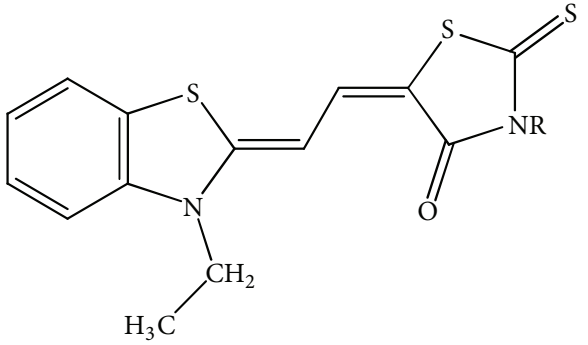

2: $\mathrm{R}=\mathrm{H}$

2a: $\mathrm{R}=\mathrm{C}_{2} \mathrm{H}_{5}$

Scheme 1: Chemical structure of the dyes used.

is often difficult to keep a molecular isomer in the frozen state for further manipulation. Usually there is a preferred isomer form of the molecule which is stable under certain conditions; however, some factors can influence this stability and change the isomer form. It has been observed that solvent polarity is one of such factors, which influences cis-trans isomerization reaction of merocyanines; this fact was explained by the effect of solvent polarization on the intramolecular motion [12]. Thermalization and photo-excitation are other factors which influence isomerization of merocyanines [13].

The purpose of this study is to investigate the effect of dye concentration on molecular isomerism in polar solvents, such as dimethylformamide (DMF) and dimethyl sulfoxide (DMSO). In this work, we observed for the first time a coexistence of two monomer forms of dimethinemerocyanines in polar solvents and here we show how the relationship between these forms is affected by solvent polarity, dye concentration, and protonation.

\section{Experimental}

2.1. Dye Synthesis. 5-[(1,3,3-Trimethyl-3H-indol-2-ylidene)ethylidene]-2-thioxo-1,3-thiazolidin-4-one (1) was obtained by condensation of 2-(1,3,3-trimethylindolin-2-ylidene)acetaldehyde with rhodanine in acetic acid. The yield was $30 \%$. NMR ${ }^{1} \mathrm{H}$ (DMSO) $\delta$ (ppm): $1.56\left(\mathrm{~s}, 6 \mathrm{H}, \mathrm{CH}_{3}\right) ; 3.35$ (s, $\left.3 \mathrm{H}, \mathrm{NCH}_{3}\right) ; 5.28$ (d, $J=15.0 \mathrm{~Hz}, 1 \mathrm{H}, \mathrm{H}$-chain); 7.03 (t, $J=8.3 \mathrm{~Hz}, 1 \mathrm{H}, \mathrm{Ar}-\mathrm{H}) ; 7.13(\mathrm{~d}, J=9.0 \mathrm{~Hz}, 1 \mathrm{H}, \mathrm{Ar}-\mathrm{H}) ; 7.26(\mathrm{t}$, $J=8.3 \mathrm{~Hz}, 1 \mathrm{H}, \mathrm{Ar}-\mathrm{H}) ; 7.43(\mathrm{~d}, J=7.7 \mathrm{~Hz}, 1 \mathrm{H}, \mathrm{Ar}-\mathrm{H}) ; 7.66$ (d, $J=15.0 \mathrm{~Hz}, 1 \mathrm{H}, \mathrm{H}$-chain); 13.15 (s, 1H, NH). Elemental analysis calcd (\%) for $\mathrm{C}_{16} \mathrm{H}_{16} \mathrm{~N}_{2} \mathrm{OS}_{2}$ (316.44): $\mathrm{C} 60.72, \mathrm{H}$ 5.09, S 20.26; found: C 61.02, H 4.98, S 20.32 .

5-[(1,3,3-Trimethyl-3H-indol-2-ylidene)ethylidene]-3ethyl-2-thioxo-1,3-thiazolidin-4-one (1a) was obtained in an analogous way using $\mathrm{N}$-ethylrhodanine instead of rhodanine. $\mathrm{NMR}{ }^{1} \mathrm{H}\left(\mathrm{CDCl}_{3}\right) \delta(\mathrm{ppm}): 1.29\left(\mathrm{t}, J=6.0 \mathrm{~Hz}, 3 \mathrm{H}, \mathrm{CH}_{3}\right)$; $1.66\left(\mathrm{~s}, 6 \mathrm{H}, \mathrm{CH}_{3}\right) ; 3.32\left(\mathrm{~s}, 3 \mathrm{H}, \mathrm{NCH}_{3}\right) ; 4.19(\mathrm{q}, J=6.7 \mathrm{~Hz}, 2 \mathrm{H}$, $\left.\mathrm{CH}_{2}\right) ; 5.17(\mathrm{~d}, J=16.5 \mathrm{~Hz}, 1 \mathrm{H}, \mathrm{H}$-chain); $6.86(\mathrm{~d}, J=6.7 \mathrm{~Hz}$, $1 \mathrm{H}, \mathrm{Ar}-\mathrm{H}) ; 7.07$ (t, $J=6.7 \mathrm{~Hz}, 1 \mathrm{H}, \mathrm{Ar}-\mathrm{H}) ; 7.24-7.28$ (m, 2H, $\mathrm{Ar}-\mathrm{H}) ; 7.91$ (d, $J=16.5 \mathrm{~Hz}, 1 \mathrm{H}, \mathrm{H}$-chain). Elemental analysis calcd (\%) for $\mathrm{C}_{18} \mathrm{H}_{20} \mathrm{~N}_{2} \mathrm{OS}_{2}$ (344.49): C 62.75, $\mathrm{H}$ 5.85, N 8.13; found: C 63.11, H 5.57, N 8.18.

[(3-Ethylbenzothiazolyl-2-ylidene)ethylidene]-2-thioxo1,3-thiazolidin-4-one (2) was obtained by boiling of a mixture of $0.225 \mathrm{~g}(0.5 \mathrm{mM})$ of 2-acetanilidovinyl-3-ethylbenzothiazolium iodide, $0.073 \mathrm{~g}(0.55 \mathrm{mM})$ of rhodanine, and $0.051 \mathrm{~g}$ $(0.5 \mathrm{mM})$ of triethylamine in $5 \mathrm{~mL}$ of dry ethanol for 1.5 hours. After cooling down of the mixture, the dye was filtered out and washed by ethanol. Crystallization of the dye was obtained using DMF. The yield was $0.15 \mathrm{~g}(92 \%)$, the melting point above $210^{\circ} \mathrm{C}$. The same dye has been obtained previously by condensation of 5 -acetanilidomethylene-rhodanine with 2-methyl-3-ethyl-benzothiazolium iodide with the yield of $50 \%$ [14]. NMR ${ }^{1} \mathrm{H}$ (DMSO) $\delta(\mathrm{ppm}): 1.23(\mathrm{t}, J=6.9 \mathrm{~Hz}$, $\left.3 \mathrm{H}, \mathrm{CH}_{3}\right) ; 4.20\left(\mathrm{q}, J=6.9 \mathrm{~Hz}, 2 \mathrm{H}, \mathrm{CH}_{2}\right) ; 5.64(\mathrm{~d}, J=13.2 \mathrm{~Hz}$, $1 \mathrm{H}, \mathrm{H}$-chain); $7.22(\mathrm{t}, J=7.8 \mathrm{~Hz}, 1 \mathrm{H}, \mathrm{Ar}-\mathrm{H}) ; 7.29(\mathrm{~d}$, $J=12.6 \mathrm{~Hz}, 1 \mathrm{H}, \mathrm{H}$-chain); $7.42(\mathrm{t}, J=8.1 \mathrm{~Hz}, 1 \mathrm{H}, \mathrm{Ar}-\mathrm{H})$; $7.46(\mathrm{~d}, J=7.5 \mathrm{~Hz}, 1 \mathrm{H}, \mathrm{Ar}-\mathrm{H}) ; 7.77(\mathrm{~d}, J=7.5 \mathrm{~Hz}, 1 \mathrm{H}$, Ar-H); 13.02 (s, 1H, NH). Elemental analysis calcd (\%) for $\mathrm{C}_{14} \mathrm{H}_{12} \mathrm{~N}_{2} \mathrm{OS}_{3}$ (320.45): $\mathrm{N}$ 8.74, S 30.02; found: $\mathrm{N}$ 9.01; $\mathrm{S}$ 29.79 .

[(3-Ethylbenzothiazolyl-2-ylidene)ethylidene]-3-ethyl-2thioxo-1,3-thiazolidin-4-one (2a) has been obtained in a way similar to 2, using $\mathrm{N}$-ethylrhodanine instead of rhodanine, as described in [15]. NMR ${ }^{1} \mathrm{H}$ (DMSO) $\delta(\mathrm{ppm}): 1.16(\mathrm{t}$, $\left.J=7.6 \mathrm{~Hz}, 3 \mathrm{H}, \mathrm{CH}_{3}\right) ; 1.25\left(\mathrm{t}, J=8.0 \mathrm{~Hz}, 3 \mathrm{H}, \mathrm{CH}_{3}\right) ; 4.02(\mathrm{q}$, $\left.J=7.2 \mathrm{~Hz}, 2 \mathrm{H}, \mathrm{CH}_{2}\right) ; 4.26\left(\mathrm{q}, J=8.0 \mathrm{~Hz}, 2 \mathrm{H}, \mathrm{CH}_{2}\right) ; 5.79(\mathrm{~d}$, $J=12.4 \mathrm{~Hz}, 1 \mathrm{H}, \mathrm{H}$-chain); $7.27(\mathrm{t}, J=7.6 \mathrm{~Hz}, 1 \mathrm{H}, \mathrm{Ar}-\mathrm{H})$; 7.44-7.54 (m, 3H, Ar-H, H-chain); 7.83 (d, $J=7.6 \mathrm{~Hz}$, $1 \mathrm{H}, \mathrm{Ar}-\mathrm{H})$. Elemental analysis calcd (\%) for $\mathrm{C}_{16} \mathrm{H}_{16} \mathrm{~N}_{2} \mathrm{OS}_{3}$ (348.04): N 8.04, S 27.60; found: N 7.89; S 27.44. Refer to Scheme 1 for the chemical structures of the synthesized dyes.

2.2. Measurements. Electronic absorption and photoluminescence (PL) spectra were measured using an AvaSpec2048 spectrometer, with the pure solvent as a reference sample. All the solvents used were of spectrograde quality. The measurements of sample and reference solutions were conducted using the same cuvette. A halogen lamp was used for measurements of electronic absorption and a diode laser with excitation wavelength at $408 \mathrm{~nm}$ was used for excitation of the emission spectra.

Studies on the effect of side irradiation of the solutions on their electronic absorption spectra were performed using the wavelength of $408 \mathrm{~nm}$ from the laser and $510 \mathrm{~nm}$ from the halogen lamp through a bandpass filter (FWHM $=25 \mathrm{~nm}$ ), while using a white probing light. Electronic absorption experiment with the gated pumping of the probing light has 


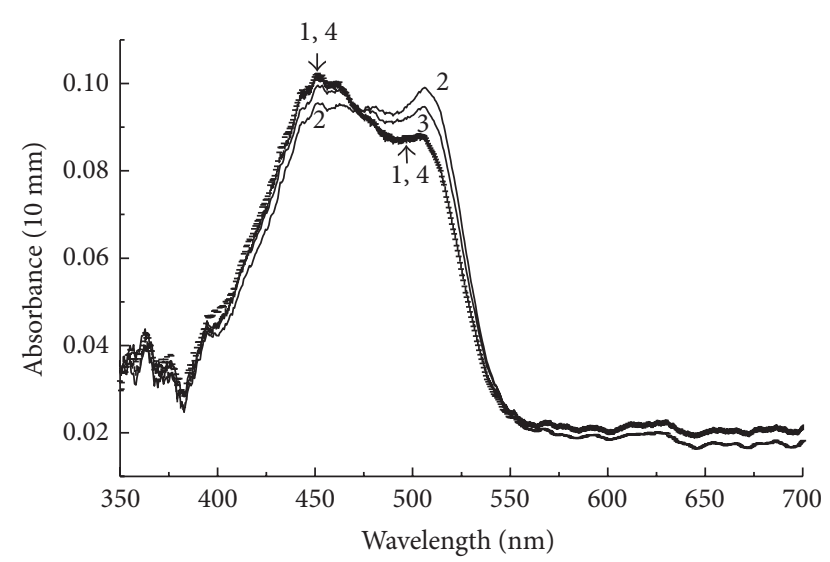

FIGURE 1: Changes in electronic absorption profiles of DMF solution of $1\left(2.2 \times 10^{-6} \mathrm{M}\right)$ : (1, vertical bars) - as-prepared solution; (2)after irradiation of the solution (1) with the wavelength $408 \mathrm{~nm}$ for 5 min.; (3)-after mechanical shaking of the solution (2); (4, horizontal bars) - after irradiation of the solution (3) with the wavelength $510 \mathrm{~nm}$ for $10 \mathrm{~min}$.

been performed through change of the continuous probing irradiation by the pulsed one with the same length of strobe, but different duty factors.

\section{Results}

3.1. Photo- and Thermoisomerization Processes. Electronic absorption spectra of the solutions of compounds 1 and 2 revealed their two-band structure at relatively small concentrations $\left(<10^{-5} \mathrm{M}\right)$ in polar solvents such as DMF. For example, DMF solution of $\mathbf{1}$ was found to have a short wavelength band at $\sim 450 \mathrm{~nm}$ and a long wavelength counterpart at $\sim 510 \mathrm{~nm}$ (Figure 1, curve 1). It has been found that the intensity ratio of these components can vary depending on the conditions influencing the solution. In this section, we focus only on changes in the above ratio as a result of some energetic influence on the solution.

First, irradiation of the as-prepared solution with the wavelength at $408 \mathrm{~nm}$ resulted in reduction of the short wavelength band and increase of the long wavelength one (Figure 1, compare curves 1 and 2). A subsequent careful shake of the solution by hand resulted in partial recovery of the initial spectrum (Figure 1, curve 3). Finally, irradiation of the solution with the wavelength at $510 \mathrm{~nm}$ resulted in further reduction of the long wavelength band and increase in the short wavelength one, so that the spectrum completely recovered to the initial one (Figure 1, curve 4). It should be noted that similar changes have been found upon irradiation of the solution of the related dyes by Takayanagi et al., which were explained by the molecular isomerization processes [3]. Therefore, one can conclude that dye molecules in our case undergo analogous transformations between two isomers under the light influence. An isosbestic point at $472 \mathrm{~nm}$ (Figure 1) supports this conclusion, since it indicates that only two molecular forms are present in the solution. The mechanism of the above changes upon the light influence originates from the tendency of the thermodynamic system

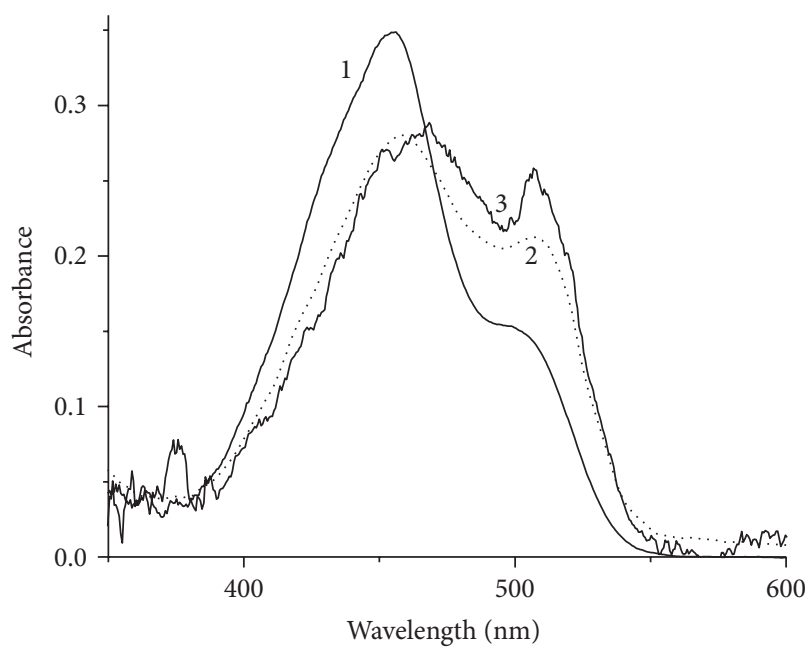

FIGURE 2: Electronic absorption of DMF solution of $\mathbf{1}$ (ca. $8 \times$ $10^{-6} \mathrm{M}$ ) with the different duty factor of the gated probing irradiation: (1) $100 \%$; (2) $0.05 \%$; (3) $0.0005 \%$. Duration of a single strobe for (2) and (3) was $5 \mu \mathrm{s}$.

to evolve to the state with the minimum of free energy; however, the details of this mechanism are a separate subject of investigation and will not be discussed here.

Electronic absorption experiment with the gated pumping of the probing light showed dependence of the spectrum profile on the duty factor. Namely, the relative contribution of the short-wavelength band in the spectrum was decreasing, while the relative contribution of the long-wavelength band was increasing upon reducing the duty factor (Figure 2). Moreover, position of the maximum of the short-wavelength band was changing, being 455,458 , and $468 \mathrm{~nm}$ for the duty factor of $100 \%, 0.05 \%$, and $0.0005 \%$, respectively, whereas position of the long-wavelength band was virtually the same. That means that excitation of the molecules by irradiation changes their equilibrium in the solvent environment and causes some long-lived molecular states which contribute to the spectrum more as the duty factor increases. In principle, an unaffected spectrum could be obtained only upon excitation with the negligibly small duty factor/pulse duration of the pumping irradiation.

In order to check whether molecular mobility influences the above effect, the spectrum has been monitored during heating of the sample solution. It has been found that heating indeed influences the electronic spectrum, although the changes upon heating to $\sim 80^{\circ} \mathrm{C}$ are modest. Meanwhile, it can be clearly observed that heating suppresses the high-energy band, promotes the low-energy one, and yields an increasing ratio of the low-energy to high energy bands, respectively (Figure 3). Thus, heating influences the solution spectrum, although its mechanism can be different from that induced by light irradiation considered above.

3.2. Effect of Aggregation on Electronic Absorption Spectra in Nonpolar Solvents. It should be noted first that similar spectral changes of solutions of $\mathbf{1}$ and $\mathbf{2}$ have been found in polar solvents upon concentration changes; these changes 


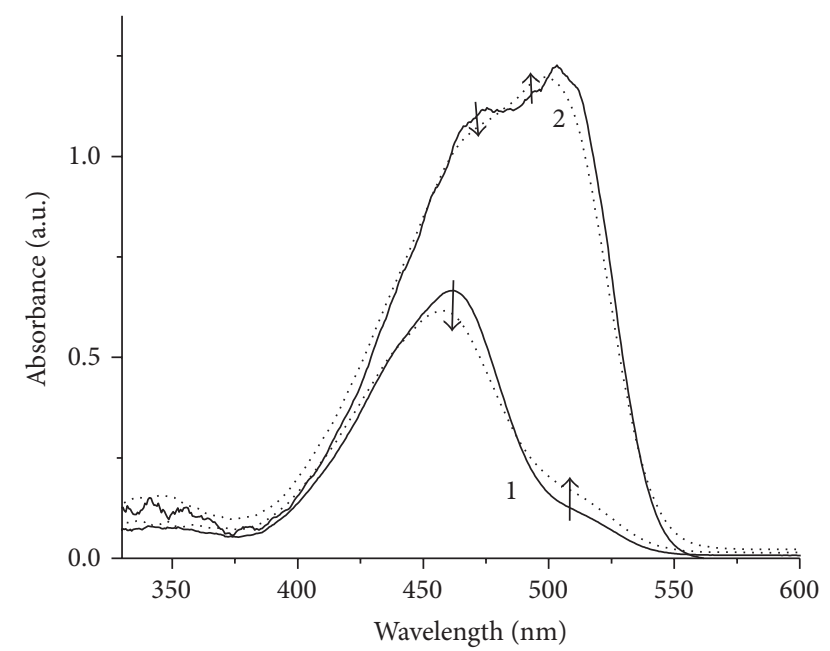

FIGURE 3: Changes in electronic absorption spectra of DMSO solutions of 1 upon solution heating from room temperature (solid curves) to $\sim 80^{\circ} \mathrm{C}$ (dotted curves): (1) $10^{-5} \mathrm{M}$; (2) $2.2 \times 10^{-5} \mathrm{M}$.

will be considered in more detail in a subsequent section. In this section, the spectral features of molecular aggregation of the dyes in nonpolar solvents, such as toluene and oxylene, are studied. Spectra of the diluted solutions $\left(\leq 10^{-6} \mathrm{M}\right)$ indicated only the monomer features in the form of a single absorption band with the maximum at $\sim 487 \mathrm{~nm}$ (Figure 4, curve 1). The signs of aggregation of the molecules were observed upon increasing their concentration in the solution to $>10^{-4} \mathrm{M}$. Namely, the increase in concentration resulted in gradual decrease of the molar extinction coefficient accompanied by a deformation of the spectral shape, that is, band broadening and appearance of the short-wavelength absorption component at $\sim 440 \mathrm{~nm}$ (Figure 4 , curves 2 and $3)$. These changes are indicative of the formation of dye aggregates and attributable to typical spectral changes for many other dyes [16-18].

3.3. Effect of the Polar Solvents on Spectral Changes as a Function of the Dye Concentration. The change of the toluene solvent for a more polar one, that is, DMF, resulted in drastic changes in behavior of $\mathbf{1}$ and $\mathbf{2}$ with increasing concentration. Small concentrations revealed the presence of a short-wavelength band at $\sim 460 \mathrm{~nm}$ for 1 accompanied with a shoulder at the long wavelength side of the absorption band $(\sim 508 \mathrm{~nm})$. The molar extinction coefficient for this band decreases upon increasing concentration and is accompanied with increasing intensity of the long-wavelength band which becomes dominant at high $\left(10^{-4} \mathrm{M}\right)$ concentrations (Figure 5(a)). It should be noted that no remarkable broadening of the absorption band is observed in the above range $\left(10^{-6}\right.$ to $\left.10^{-4} \mathrm{M}\right)$ of concentrations; that is indicative of the monomer behavior of the dye in the solution. The above spectral changes also demonstrate an isosbestic point which evidences that the molecule possesses two forms which transform to each other. Further increase of concentration resulted in broadening of the spectrum and reducing molar extinction coefficient (Figure 5(a), curve 6). The latter changes indicate

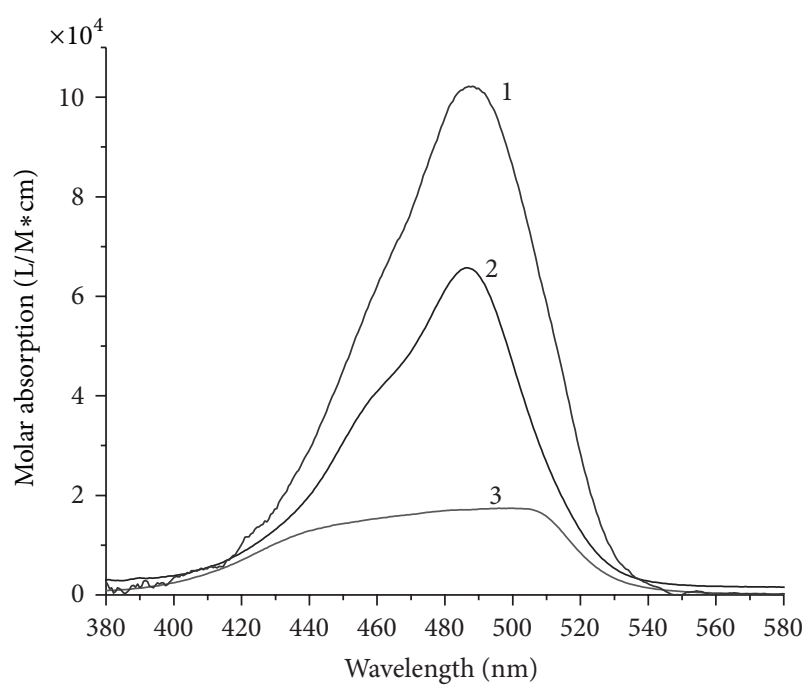

Figure 4: Molar extinction coefficient of toluene solutions of dye $\mathbf{1}$ : (1) $-1 \times 10^{-6} \mathrm{M}$; (2) $-1 \times 10^{-4} \mathrm{M}$; (3) $-1 \times 10^{-3} \mathrm{M}$.

the formation of molecular aggregates as was shown above in case of nonpolar solvents.

Similar changes have been observed for DMF solutions of 2 (Figure 5(b)). Small concentrations showed a shortwavelength band at $\sim 475 \mathrm{~nm}$ accompanied with a shoulder at $\sim 524 \mathrm{~nm}$. The molar extinction coefficient for the shortwavelength band decreases upon increasing concentration and is accompanied with increasing intensity of the longwavelength band which becomes dominant at high $\left(10^{-4} \mathrm{M}\right)$ concentrations. Again, no remarkable broadening of the absorption band is observed in the above range (up to $10^{-4} \mathrm{M}$ ) of concentrations which indicates the monomer-like behavior of $\mathbf{2}$ in the solution. The above spectral changes also demonstrate an isosbestic point at $495 \mathrm{~nm}$, which indicates that the molecule possesses two forms which transform to each other. Further increase of concentration resulted in broadening of the spectrum and reducing molar extinction coefficient (Figure 5(b), curve 6). These changes point out formation of molecular aggregates.

It should be noted that a similar spectral behavior depending on dye concentration was found on using other polar solvents, namely, DMSO (not shown) and N-methylpyrrolidinone (NMP) Figure 5(c). Despite the above similarity of behavior of $\mathbf{1}$ and $\mathbf{2}$ in DMF or DMSO solutions, these dyes demonstrate different behavior in aqueous medium. Addition of a small amount of DMF solution of 1 to water (DMF to water 1:100 vol.\%) resulted in strengthening of the long-wavelength band of the dye (Figure 5(a), curve 7), which cannot be explained by molecular association, since the molar extinction coefficient did not decrease there. On the other hand, 2 showed suppression of the long-wavelength band and increase of the short-wavelength one accompanied with the overall decrease in the molar extinction coefficient in the aqueous medium (Figure 5(b), curve 7); the latter changes are characteristic of formation of aggregates.

On the other hand, the related alkyl-substituted dyes (1a and 2a) showed no qualitative changes in spectra as a function 


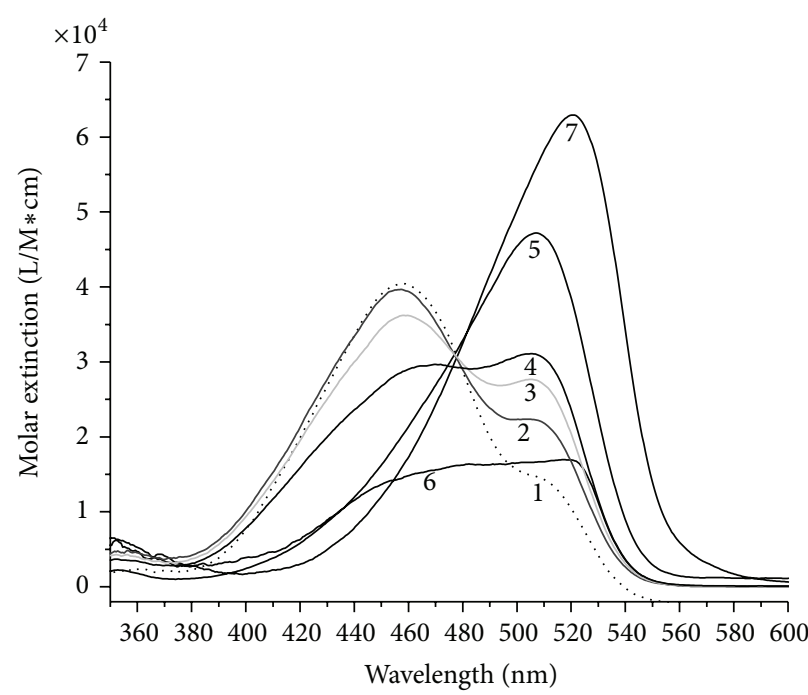

(a)

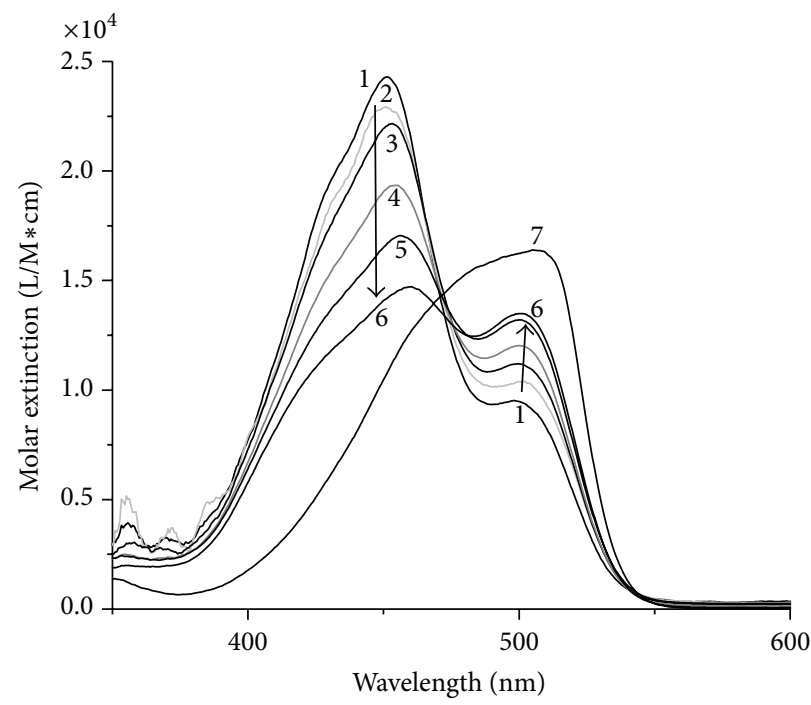

(c)

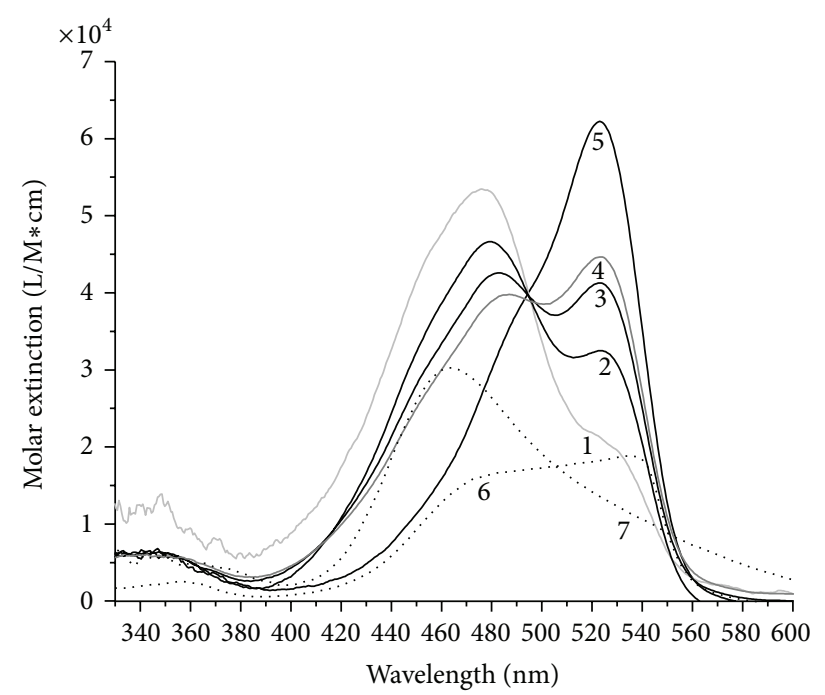

(b)

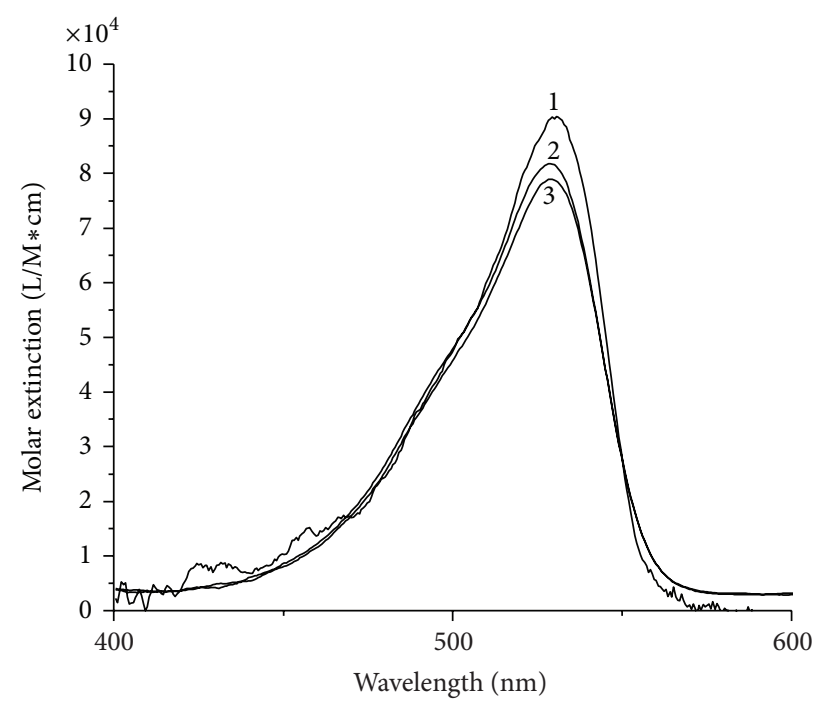

(d)

Figure 5: Molar extinction coefficient of solutions of (a) 1 in DMF: (1) $-10^{-5} \mathrm{M}$; (2) $-2.0 \times 10^{-5} \mathrm{M}$; (3) $-2.9 \times 10^{-5} \mathrm{M}$; (4) -4.8 $\times 10^{-5} \mathrm{M}$; (5) $-1.0 \times 10^{-4} \mathrm{M}$; (6) $-1.0 \times 10^{-3} \mathrm{M}$; (7) $-1.0 \times 10^{-5} \mathrm{M}$ in binary solution of DMF/water $(1: 100$ vol.\%). An isosbestic point at $478 \mathrm{~nm}$ clearly evidences two forms of the dye molecules in the DMF solution at moderate concentrations; (b) 2 in DMF: (1) - $9.1 \times 10^{-7} \mathrm{M}$; $(2)-1.0 \times 10^{-5} \mathrm{M}$; (3) $-2.1 \times 10^{-5} \mathrm{M}$; (4) $-3.15 \times 10^{-5} \mathrm{M}$; (5) $-1.0 \times 10^{-4} \mathrm{M}$; (6) - $1.0 \times 10^{-3} \mathrm{M}$; (7) - $1.0 \times 10^{-5} \mathrm{M}$ in binary solution of DMF/water (1:100 vol.\%). An isosbestic point at $494 \mathrm{~nm}$ clearly evidences two forms of the dye molecules in the DMF solution at moderate concentrations; (c) 1 in

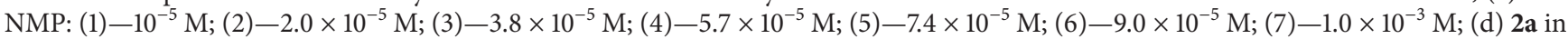
DMF: (1) $-10^{-6} \mathrm{M}$; (2) $-10^{-5} \mathrm{M}$; (3) $-10^{-4} \mathrm{M}$.

of their concentration. Only a single pronounced band located at $\sim 507 \mathrm{~nm}$ for $1 \mathbf{a}$ and $\sim 530 \mathrm{~nm}$ for $2 \mathrm{a}$ (Figure 5(d)) was found in the wide range of the dye concentrations.

\subsection{Effect of Protonation on Spectral Changes of the Dye Solu-} tions. Addition of a small amount of acid $(\mathrm{HCl})$ resulted in significant spectral changes of both $\mathbf{1}$ and $\mathbf{2}$ taken at relatively small dye concentration of $10^{-5} \mathrm{M}$ (Figure 6). Acid induced almost a complete suppression of the short wavelength band and increase in intensity of the long wavelength band. The analogous changes have been found in PL spectra of the solutions, which consist of two bands in initial DMF solution, originating from relaxation of the excited electrons responsible for the short wavelength and long wavelength absorption band, respectively. Acid addition resulted in the complete suppression of the short-wavelength PL band, respectively (Figure 7). The above results present evidence in favor of the fact that the emission centers responsible for the different PL bands are independent.

No change was induced by acid addition to solutions of alkyl-substituted dyes (1a and $\mathbf{2 a}$ ). The spectra were essentially the same even after the acid addition (Figure 8). 


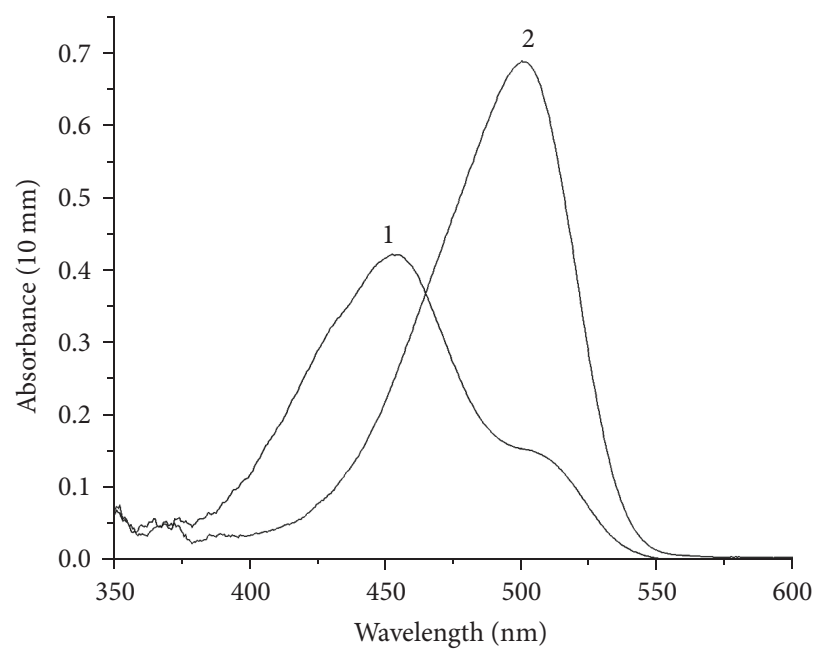

(a)

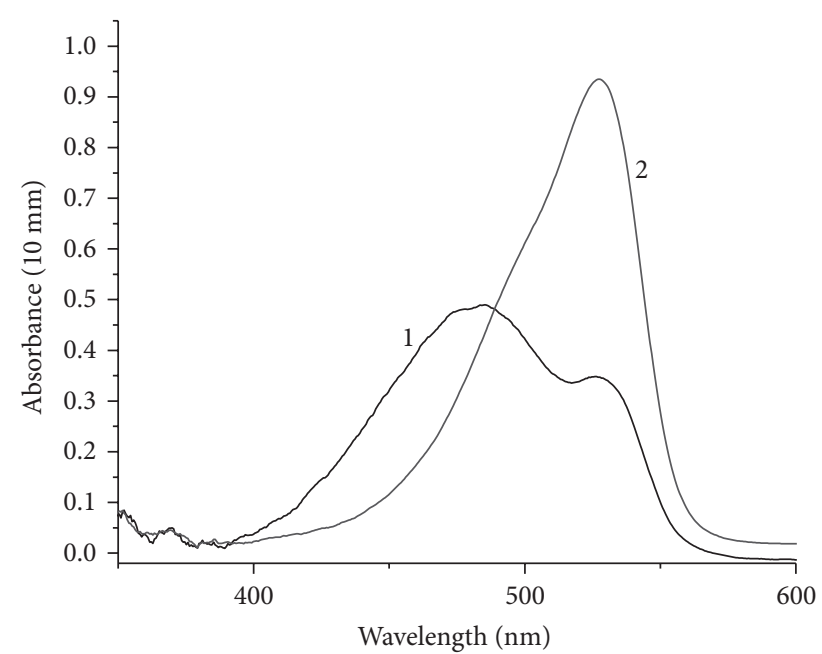

(b)

Figure 6: Electronic absorption of (a) $\mathbf{1}\left(10^{-5} \mathrm{M}\right)$ and (b) $2\left(10^{-5} \mathrm{M}\right)$ in (1) neutral DMF and (2) after addition of $\mathrm{HCl}$ to the solution. The molar ratio of $\mathrm{HCl}$ to dye was $10: 1$.

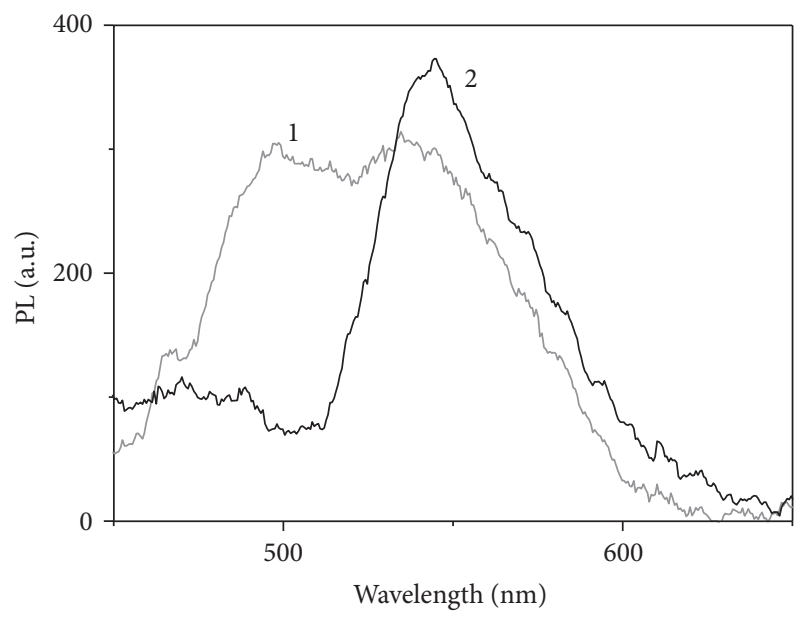

Figure 7: PL emission of $\mathbf{1}\left(10^{-5} \mathrm{M}\right)$ in neutral DMF (1) and after addition of $\mathrm{HCl}$ to the solution (2). The molar ratio of $\mathrm{HCl}$ to dye was $10: 1$.

\section{Discussion}

As was noted, the reason of the above spectral changes in $\mathbf{1}$ and 2 with increase of their concentration should be assigned to molecular isomerization processes, rather than to molecular aggregation. First, one should not expect significant aggregation of dye molecules within relatively small concentrations $\left(10^{-6}-10^{-4} \mathrm{M}\right)$. As was shown (Figure 4), aggregation of the above dyes leads to the band broadening and decreasing molar absorption coefficient rather than appearance of a new band. Spectral changes of $\mathbf{1 a}$ and 2a (Figure 5(d)) confirm that no additional band should appear within the concentration range of $10^{-6}-10^{-4} \mathrm{M}$. Moreover, formation of dimers of related merocyanines in the form of a stack leads to the appearance of a blue-shifted band [19], which is opposite to spectral behavior of the investigated dyes upon increasing concentration. Second, the spectral changes in molar extinction coefficient of $\mathbf{1}$ and $\mathbf{2}$ go through isosbestic point which is a clear evidence of the presence of two forms of monomers in the solutions at small concentrations. Third, the independent quenching of PL emission bands evidences independent molecular forms responsible for these bands.

There are four possible isomers of the considered dyes because of the different mutual positions of their end groups due to rotation around $\mathrm{C}_{1}=\mathrm{C}_{2}$ and $\mathrm{C}_{3}=\mathrm{C}_{4}$ bonds, respectively (Scheme 2). Takayanagi et al. [3] have showed that two absorption bands with the short- and long-wavelength components in electronic spectra for a similar dye molecule correspond to isomers II and I, respectively. We take this result as a basis for interpretation of our spectra and assign the short-wavelength and the long-wavelength absorption bands in dyes $\mathbf{1}$ and $\mathbf{2}$ to isomers II and I in Scheme 2, respectively.

It should be noted that Takayanagi et al. [3] have studied $\mathbf{2 a}$ in cyclohexane solution and concluded that the preferred form for this dye (at small concentration of $6.5 \times 10^{-6} \mathrm{M}$ ) and also in the solid state (crystals or films) is the isomer II (Scheme 2). This conclusion is not consistent with our observation which indicates that 2 a should be present as isomer I in polar solvents (Figures 5(d) and 8(b)). However, our results indicate that the isomer II should prevail for the dye 2 in polar solvents at small concentrations (Figure 5(b)). Therefore, substitution at the nitrogen atom of the rhodanine moiety has a great effect on the molecular isomerization. We assign this effect to specific interaction of the dye and solvent molecules. Dyes $\mathbf{1}$ and $\mathbf{2}$ are able to form hydrogen bonds with polar solvent molecules such as DMF, while dyes $\mathbf{1 a}$ and $\mathbf{2} \mathbf{a}$ are not, since the proton near the nitrogen atom is substituted there by ethyl radicals. Formation of the H-bonds in $\mathbf{1}$ and $\mathbf{2}$ shifts the electronic density along the molecular backbone of the dye and this effect leads to hindering rotation of the rhodanine moiety around the $\mathrm{C}=\mathrm{C}$ bond of the central conjugated system to achieve the stable 


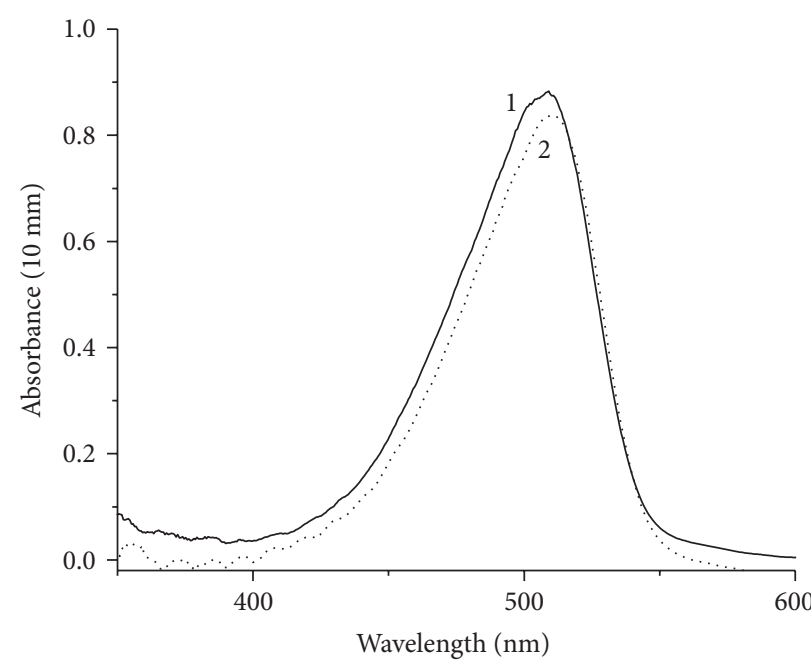

(a)

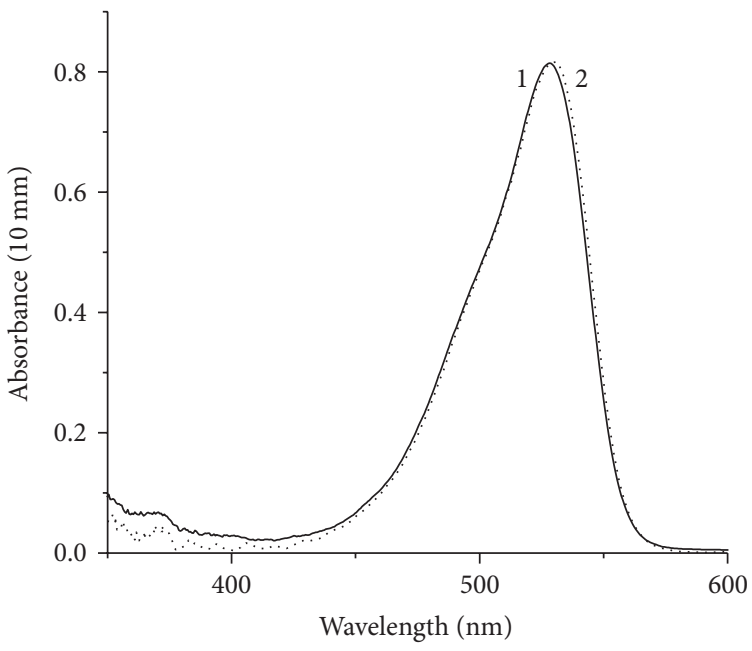

(b)

FIGURE 8: Effect of protonation on electronic absorption spectra of (a) 1a and (b) 2a in DMF: (1) - no acid; (2) - $\mathrm{HCl}$ added, molar ratio of acid to dye was $10: 1$. Dye concentration was $10^{-5} \mathrm{M}$ in all cases.<smiles></smiles>

I<smiles></smiles>

II<smiles>CCN1/C(=C\C=C2/SC(=S)NC2=O)Sc2ccccc21</smiles>

III<smiles></smiles>

IV

Scheme 2: Four possible isomers of $\mathbf{2}(\mathrm{R}=\mathrm{H})$ and $\mathbf{2 a}\left(\mathrm{R}=\mathrm{C}_{2} \mathrm{H}_{5}\right)$.

isomer form intrinsic of the dyes $\mathbf{1 a}$ and $\mathbf{2 a}$. On the other hand, rotation of the rhodanine moiety in $\mathbf{1 a}$ and $\mathbf{2 a}$ is more facilitated since the electronic density is shifted from the central conjugated system to the ethyl radical, which makes the alternating bonds in the central conjugated part of the molecule be more asymmetric. Moreover, the attached ethyl radical serves as a "lever" to rotate the molecule.

In order to facilitate rotation of the rhodanine moiety in $\mathbf{1}$ and 2, additional influence is needed. It seems that molecular collisions play the role of such an influence to induce a mutual rotation of the end groups. Indeed, increase in concentration results in transformation of isomer II to isomer I in solutions of $\mathbf{1}$ and $\mathbf{2}$ (Figure 5). This influence can be calculated based on the kinetic theory of gases [20]. According to this theory, an average amount of collisions per a second, $v$, is proportional to the molecular concentration $n$ :

$$
v=(2)^{1 / 2} \pi d^{2}\langle v\rangle n
$$

where $d$ is the effective diameter of the molecule, and $\langle v\rangle$ is its average velocity. Since the square of the velocity is 
proportional to the kinetic energy and temperature of the gas, respectively, that is,

$$
E_{\text {kin }}=\frac{m\left\langle v^{2}\right\rangle}{2}=\left(\frac{3}{2}\right) k T,
$$

it can be presented as

$$
\left\langle v^{2}\right\rangle=\frac{3 k T}{m}
$$

With consideration of (3), (1) can be rewritten as

$$
v=\left(\frac{6 k T}{m}\right)^{1 / 2} \pi d n .
$$

According to (4), the amount of collision is also dependent on the temperature of the system, but this dependence is weaker. Indeed, in order to get a comparable effect which takes place, for example, when the dye concentration is increased by a factor of two, the same effect can be achieved by increasing the absolute temperature by four times. This conclusion is consistent with results of heating of the solutions, where the observed effect is very weak (Figure 3 ). It should be noted that application of the theory of gases to liquid systems can give only qualitative conclusions, since dye molecules collide not only with each other but also with solvent molecules. Therefore, some additional coefficient should be introduced to (1) and (4). However, qualitative conclusions deduced from the above theory should be valid with respect to the solutions as well.

Viscosity of the solvent used can also contribute to the effect of molecular collisions since more viscous solvents delay molecular motion. Viscosity of DMSO and NMP is larger than viscosity of DMF by more than two times; therefore, one can expect delayed dynamics of isomer interconversion as a result of molecular collisions in DMSO and NMP as compared to DMF. The relationship of isomers can be roughly evaluated through ratio of areas under absorption bands assigned to different isomers (short wavelength and long wavelength bands in Figures 5(a) and 5(c), resp.). Figure 9 represents simulation of contribution of different isomers to electronic absorption spectra as a function of concentration of 1 in DMF and NMP. As can be seen, the conversion of isomer I to isomer II with increasing concentration occurs faster in DMF and this process is delayed in more viscous NMP. This result is consistent with the above suggestion that molecular collisions can contribute to the isomerization processes.

\section{Conclusions}

Two molecular forms of dyes $\mathbf{1}$ and $\mathbf{2}$ have been found in polar solvents of DMF, DMSO, and NMP. We suggest that these two forms are due to the specific interaction of the dye and solvent molecules. Dyes $\mathbf{1}$ and $\mathbf{2}$ are able to form hydrogen bonds with polar solvent molecules such as DMF, while dyes $\mathbf{1 a}$ and $\mathbf{2 a}$ are not, since the proton near the nitrogen atom is substituted there by ethyl radicals. Formation of the $\mathrm{H}$-bonds in $\mathbf{1}$ and $\mathbf{2}$ shifts the electronic density along

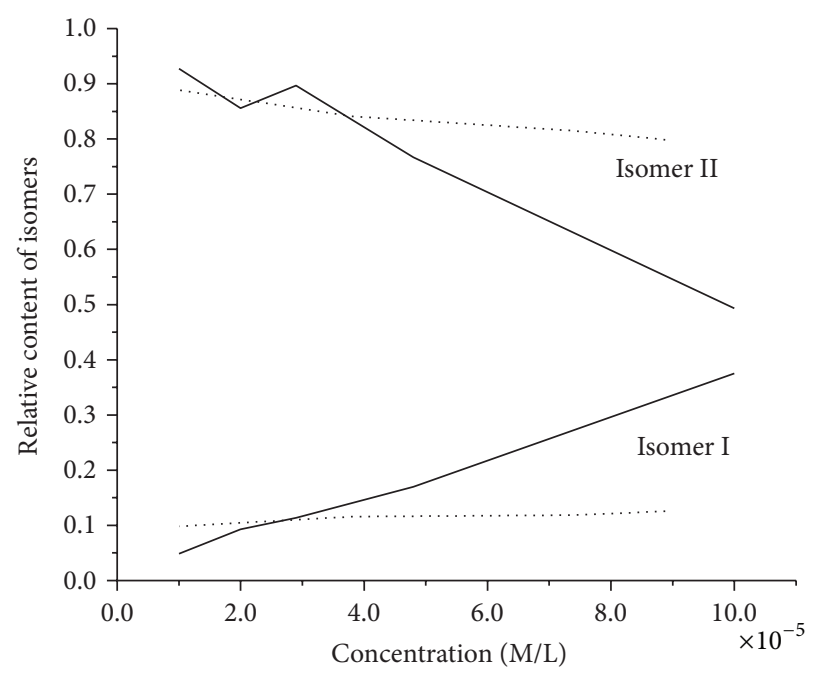

Figure 9: Relative change of isomers as a function of concentration of $\mathbf{1}$ in DMF (solid curves) and NMP (dotted curves).

the molecular backbone of the dye and this effect leads to hindering rotation of the rhodanine moiety around the $\mathrm{C}=\mathrm{C}$ bond of the central conjugated system to achieve the stable isomer form intrinsic of the dyes $\mathbf{1 a}$ and $\mathbf{2 a}$. On the other hand, rotation of the rhodanine moiety in $\mathbf{1 a}$ and $\mathbf{2 a}$ is more facilitated since the electronic density is shifted from the central conjugated system to the ethyl radical, which makes the alternating bonds in the central conjugated part of the molecule be more asymmetric. On the other hand, molecular collisions which are proportional to the dye concentration can influence a mutual rotation of the end groups of the dye molecule; therefore, the increase in dye concentration facilitates rotation of the rhodanine moiety and has the effect on molecular isomerization as well.

\section{Conflict of Interests}

The authors declare that there is no conflict of interests regarding the publication of this paper.

\section{Acknowledgment}

The work has been supported by STCU Project no. 4570.

\section{References}

[1] A. V. Kulinich and A. A. Ischenko, "Merocyanine dyes: synthesis, structure, properties and applications," Russian Chemical Reviews, vol. 78, no. 2, p. 141, 2009.

[2] J. O. Morley, R. M. Morley, and A. L. Fitton, "Spectroscopic studies on Brooker's merocyanine," Journal of the American Chemical Society, vol. 120, no. 44, pp. 11479-11488, 1998.

[3] M. Takayanagi, M. Nakata, Y. Ozaki, K. Iriyama, and M. Tasumi, "Conformational analysis and photoisomerization of merocyanine dyes studied by visible absorption, resonance Raman and IR spectroscopies," Journal of Molecular Structure, vol. 405, no. 2-3, pp. 239-246, 1997. 
[4] C. Reichardt, Solvent Effects in Organic Chemistry, Verlagsgesellshaft, Weinheim, Germany, 1990.

[5] G. Klopman, "Solvations: a semi-empirical procedure for including solvation in quantum mechanical calculations of large molecules," Chemical Physics Letters, vol. 1, no. 5, pp. 200-202, 1967.

[6] F. Momicchioli, I. Baraldi, and M. C. Bruni, "A new INDO-type procedure for conjugated non-rogid molecules. II. Extension to electronic spectra and excited-state potential curves," Chemical Physics, vol. 82, no. 1-2, pp. 229-252, 1983.

[7] S. Miertuš and O. Kysel, "Quantum-chemical study of radical ions and molecules incorporating the solvent effect comment on the method of incorporation of the solvent effect," Chemical Physics Letters, vol. 65, no. 2, pp. 395-398, 1979.

[8] A. Botrel, B. Aboab, F. Corre, and F. Tonnard, "A theoretical investigation of solvatochromism. Application to merocyanines similar to colored forms obtained by flash-photolysis of spiropyrans," Chemical Physics, vol. 194, no. 1, pp. 101-116, 1995.

[9] I. Baraldi, G. Brancolini, F. Momicchioli, G. Ponterini, and D. Vanossi, "Solvent influence on absorption and fluorescence spectra of merocyanine dyes: a theoretical and experimental study," Chemical Physics, vol. 288, no. 2-3, pp. 309-325, 2003.

[10] J. O. Morley, R. M. Morley, R. Docherty, and M. H. Charlton, "Fundamental studies on Brooker's merocyanine," Journal of the American Chemical Society, vol. 119, no. 42, pp. 10192-10202, 1997.

[11] B. Cunderlikova and L. Sikurova, "Solvent effects on photophysical properties of merocyanine 540," Chemical Physics, vol. 263, pp. 415-422, 2001.

[12] Y. Onganer, M. Yin, D. R. Bessire, and E. L. Quitevis, "Dynamical solvation effects on the cis-trans isomerization reaction: photoisomerization of merocyanine 540 in polar solvents," The Journal of Physical Chemistry, vol. 97, no. 10, pp. 2344-2354, 1993.

[13] S. T. Abdel-Halim, M. H. Abdel-Kader, and U. E. Steiner, "Thermal cis-trans isomerization of solvatochromic merocyanines: linear correlations between solvent polarity and adiabatic and diabatic transition energies," The Journal of Physical Chemistry, vol. 92, no. 15, pp. 4324-4328, 1988.

[14] Z. P. Sytnik, I. I. Levkoev, and M. V. Deichmeister, "On rhodanine derivatives of merocyanine dyes. I.Properties of methyl-methylsulphate 2-methylmercapto-5-(3'-ethyl-benzothiazolinylidene-2' -ethylidene)-thiazolynone-4," Journal of General Chemistry of the USSR, vol. 21, p. 768, 1951.

[15] M. V. Deichmeister, Z. P. Sytnik, and E. B. Lifshits, "On rhodanine derivatives of merocyanine dyes. II.Properties of dimethinemerocyanines with different heterocyclic nitrogencontaining residues," Journal of General Chemistry of the USSR, vol. 22, p. 166, 1952.

[16] O. P. Dimitriev and V. I. Vlaskin, "Changes in electronic absorption spectra of the fullerene C60 upon its molecular aggregation," Functional Materials, vol. 6, pp. 674-678, 1999.

[17] V. I. Vlaskin, O. P. Dimitriev, Z. I. Kazantseva, and A. V. Nabok, "Association of some phthalocyanines: from solutions to thin films," Thin Solid Films, vol. 286, no. 1-2, pp. 40-44, 1996.

[18] O. P. Dimitriev, A. P. Dimitriyeva, A. I. Tolmachev, and V. V. Kurdyukov, "Solvent-induced organization of squaraine dyes in solution capillary layers and adsorbed films," The Journal of Physical Chemistry B, vol. 109, no. 10, pp. 4561-4567, 2005.

[19] L. Lu, R. J. Lachicotte, T. L. Penner, J. Perlstein, and D. G. Whitten, "Exciton and charge-transfer interactions in nonconjugated merocyanine dye dimers: novel solvatochromic behavior for tethered bichromophores and excimers," Journal of the American Chemical Society, vol. 121, no. 36, pp. 8146-8156, 1999.

[20] I. V. Savel'ev, The Course of the General Physics, vol. 1, Nauka, Moscow, Russia, 1982. 

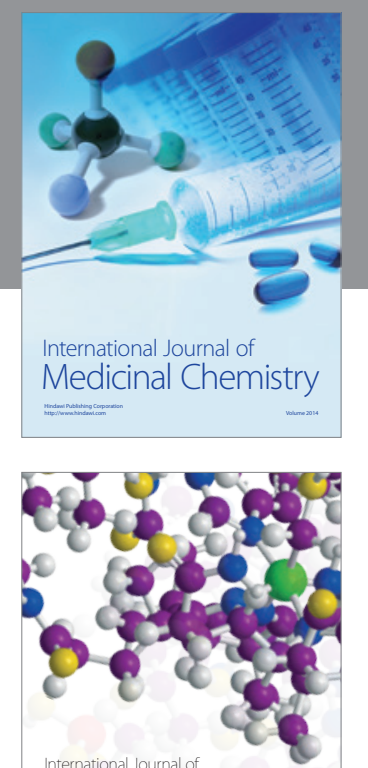

\section{Carbohydrate} Chemistry

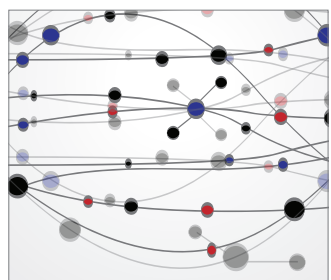

The Scientific World Journal
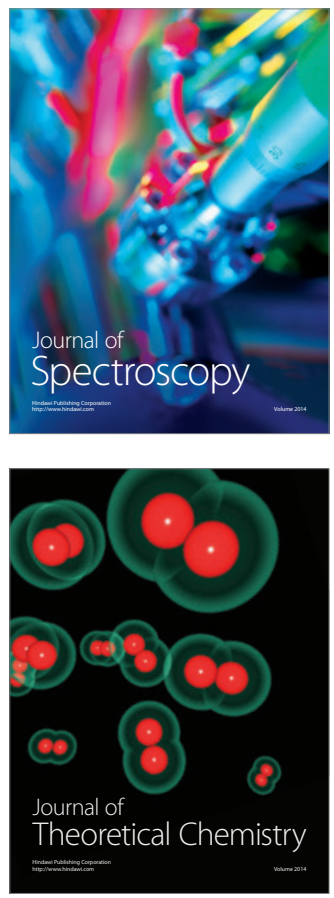
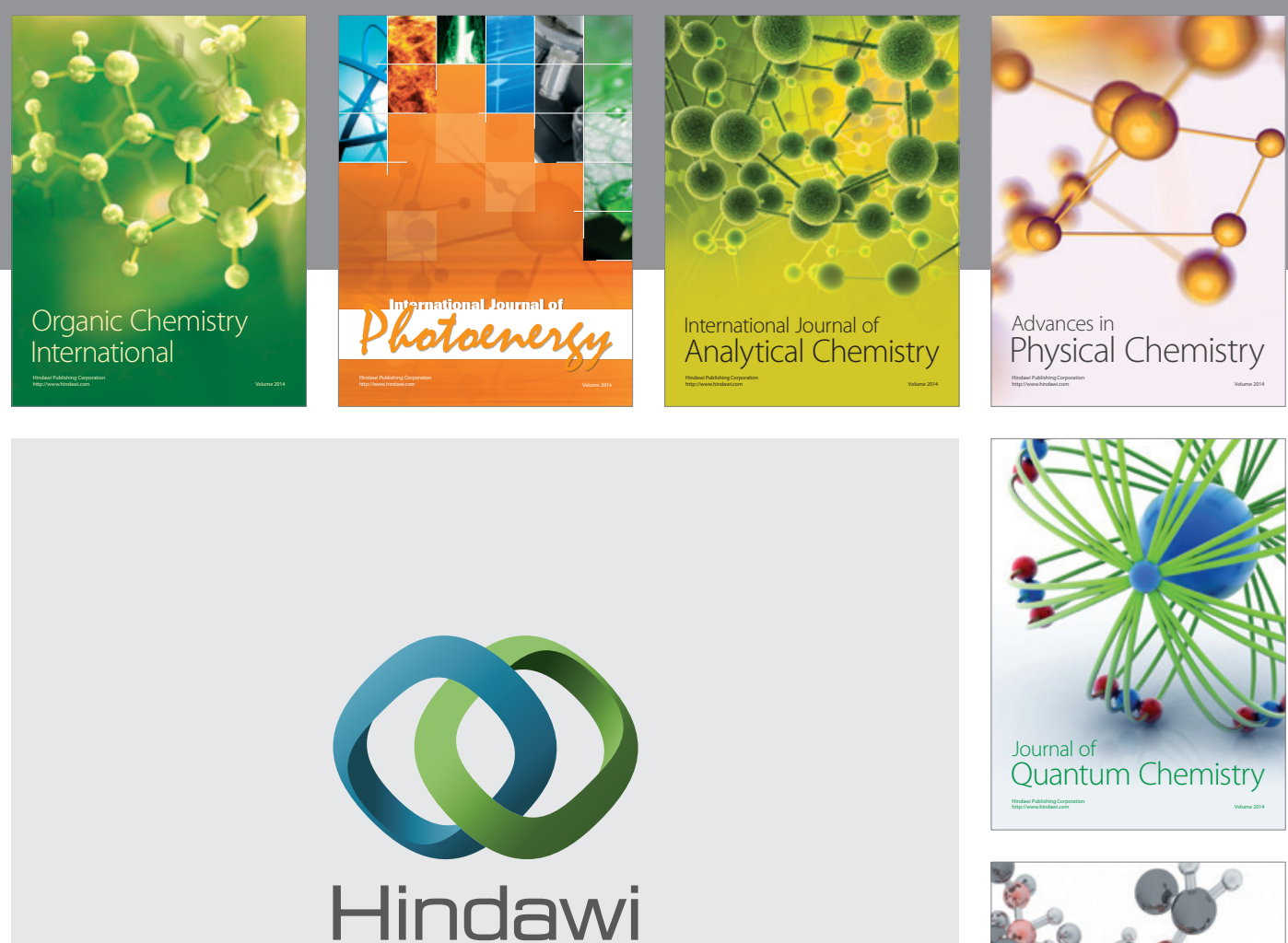

Submit your manuscripts at

http://www.hindawi.com

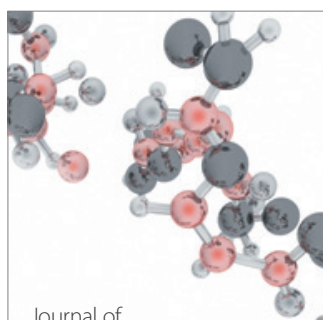

Analytical Methods

in Chemistry

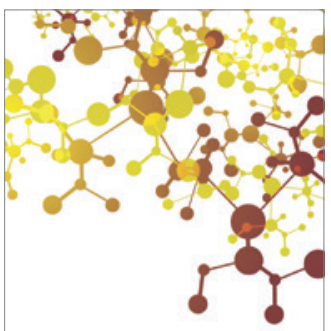

Journal of

Applied Chemistry

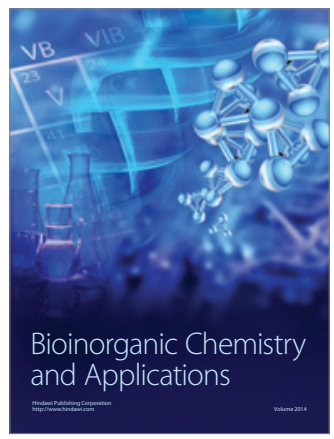

Inorganic Chemistry
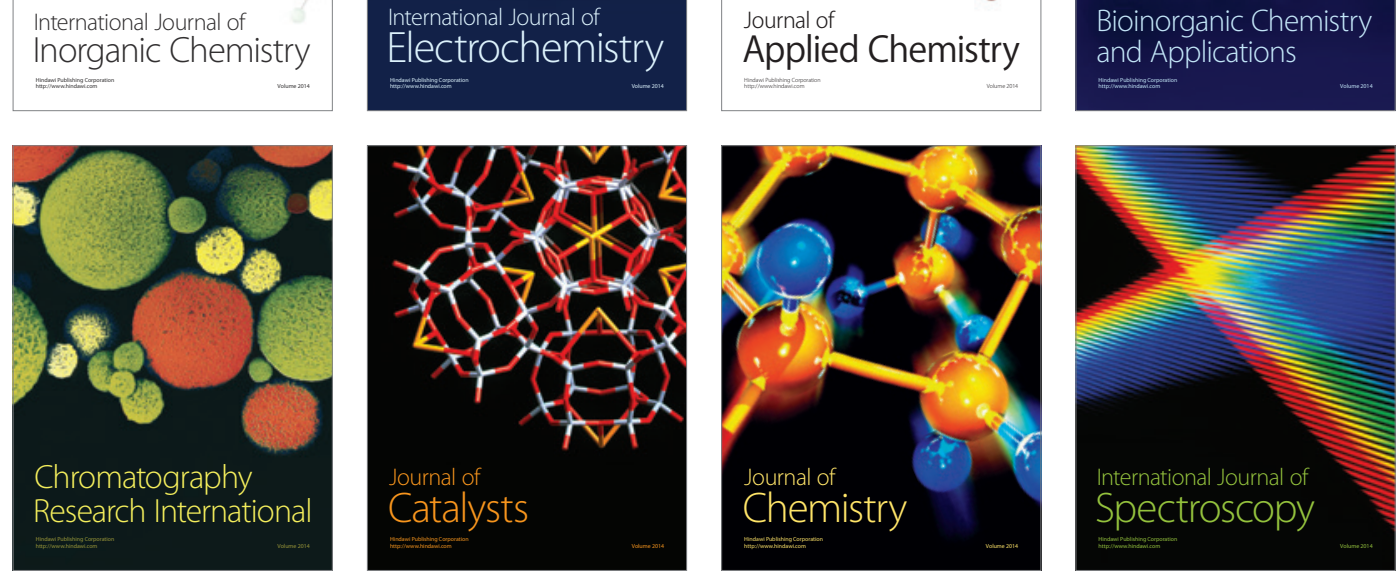